${ }^{1}$ Ecology, Department of Biology, University of Konstanz, Universtätsstraße 10, 78457 Konstanz, Germany, ${ }^{2}$ Institute of Ecology, Faculty for Sustainability, Leuphana University Lüneburg, Scharnhorststraße 1, 21335 Lüneburg, Germany, ${ }^{3}$ UFZ, Helmholtz Centre for Environmental Research UFZ, Theodor Lieser Straße 4, 06120 Halle, Germany, ${ }^{4}$ Geobotany of Botanical Garden, Martin Luther University Halle Wittenberg, Am Kirchtor 1, 06108 Halle, Germany, ${ }^{5}$ German Centre for integrative Biodiversity Research (iDiv), Am Deutschen Platz 5e, 04103 Leipzig, Germany, ${ }^{6}$ Department of Invasion Ecology, Institute of Botany, Academy of Sciences of the Czech Republic, CZ 25243 Prinhonice, Czech Republic, ${ }^{7}$ Department of Ecology, Faculty of Science, Charles University in Prague, $C Z$ 12844 Viničná 7, Prague, Czech Republic
${ }^{*}$ Correspondence: Noelie Maurel, Ecology, Department of Biology, University of Konstanz, Universtatsstrasse 10, 78457 Konstanz, Germany.

E mail: noelie.maurel@uni konstanz.de

\section{Introduction bias affects relationships between the characteristics of ornamental alien plants and their naturalization success}

Noëlie Maurel ${ }^{1 \star}$, Jan Hanspach ${ }^{2}$, Ingolf Kühn ${ }^{3,4,5}$, Petr Pyšek ${ }^{6,7}$ and Mark van Kleunen ${ }^{1}$

\begin{abstract}
Aim Alien plants with certain characteristics may have been introduced earlier and more frequently than others. Such introduction bias may cause spurious associations between plant characteristics and naturalization (the establishment of self sustaining populations in the wild). We aimed to disentangle direct and indirect (i.e. mediated by introduction history) effects of species characteristics on the naturalization success of alien plants introduced for horticulture.
\end{abstract}

Location Germany (non native range); rest of the world (native range).

Methods We compiled a dataset of 435 alien plant species introduced in cultivation in Germany, including data on their year of introduction, the number of botanical gardens where they are planted, native range, biological traits and naturalization success. We used path analysis to estimate the direct effects of geographical origin and biological traits on naturalization, and their indirect effects mediated by year and/or frequency of introduction.

Results We found significant direct positive effects of native range size and winter hardiness on naturalization. Alien species native to other parts of Europe and species with a large native range were brought to the country earlier than other species. In addition, woody species, winter hardy species and tall species were planted more frequently than others. Because the number of botanical gardens where a species is planted increased naturalization success directly, and residence time did so indirectly through a significant positive association with the number of botanical gardens, most of the species characteristics had indirect effects on naturalization.

Main conclusions Our approach allowed us to show that apparent effects of species characteristics on naturalization success can be at least partly indirect, due to introduction biases. This indicates that failure to recognize such introduction biases could impair our ability to explain the success of alien plant species.

\section{Keywords}

Establishment, exotic plants, indirect effect, neophytes, path analysis, propagule pressure, residence time. 


\section{INTRODUCTION}

Biotic exchange is a major component of global change (Leadley et al., 2010), and over 13,000 species of the global flora have become naturalized outside their native ranges due to human activity (van Kleunen et al., 2015b). Therefore, a major area of research in ecology aims to understand why some introduced alien plant species establish in the wild and others do not. Studies have therefore analysed a broad range of species characteristics, and various biological traits have been found to be associated with the success of alien plants (Pyšek \& Richardson, 2007; van Kleunen et al., 2010a). How ever, only a few characteristics show consistent patterns across studies, making the overall findings rather ambiguous.

In addition to intrinsic idiosyncrasies of plant invasions, a lack of consistent findings among studies may have several other causes. First, species are introduced to different habi tats, and the characteristics that matter for invasion thus have to be context dependent (Pyšek \& Richardson, 2007; Kueffer et al., 2013). Second, species have to overcome differ ent barriers to proceed from one invasion stage to the next. They first have to be introduced to the target range, then they have to establish self sustaining populations (i.e. natu ralize) and ultimately they have to rapidly spread there to become invasive (Blackburn et al., 2011). Different suits of characteristics might be advantageous for crossing these dif ferent barriers in the invasion process (Richardson \& Pyšek, 2012; van Kleunen et al., 2015a). Third, to identify the char acteristics driving the success of alien plant species, studies have used different types of comparisons (e.g. alien versus native species, or naturalized versus non naturalized alien species). While the sets of species that are being compared determine the question that can be addressed, this crucial aspect has frequently been neglected (Cassey et al., 2004a; van Kleunen et al., 2010b). Finally, both time since introduc tion (Pyšek et al., 2009a; Williamson et al., 2009) and propa gule pressure (Lockwood et al., 2005; Donaldson et al., 2014) influence the success of species in their introduced range. Therefore, the introduction history should be taken into account (Phillips et al., 2010; Pyšek et al., 2015).

It is likely that the chance of a species being introduced early and planted frequently depends on certain characteris tics, including those related to its native distribution as well as its biological traits. The probability of being introduced is associated with certain species characteristics, such as body mass and population size in birds (Blackburn \& Duncan, 2001; Cassey et al., 2004b), body size in salmonid fish (Colautti, 2005) and litter size and reproductive life span in mammals (Capellini et al., 2015). Evidence for plants is scarcer, but, for example, species with fast and abundant ger mination have been preferentially introduced for cultivation (Chrobock et al., 2011). Despite the likelihood of such an 'introduction bias' (van Kleunen et al., 2015a), the search for characteristics promoting success of alien plant species has mostly focused on the later stages of the invasion process. Indeed, very few studies have addressed the earliest stages, i.e. transport and introduction (Pyšek et al., 2003; van Kleu nen et al., 2007). One of the studies that did showed that, among neophytes in the Czech Republic, those species with a mixed competitor/stress tolerator/ruderal strategy, annual species and species native to other parts of Europe had been introduced earlier than those not possessing these character istics (Pyšek et al., 2003). The major consequence of an introduction bias is that plant characteristics may not only affect the success of alien species directly, but also indirectly via their introduction history (Fig. 1a). Ignoring such poten tial biases could result in spurious associations between char acteristics and success of alien species or could obscure true associations.

Path analysis is a powerful statistical framework that allows for the simultaneous analysis of several direct and indirect relationships among variables (Shipley, 2000). Pyšek et al. (2015) have recently used path analysis to assess how
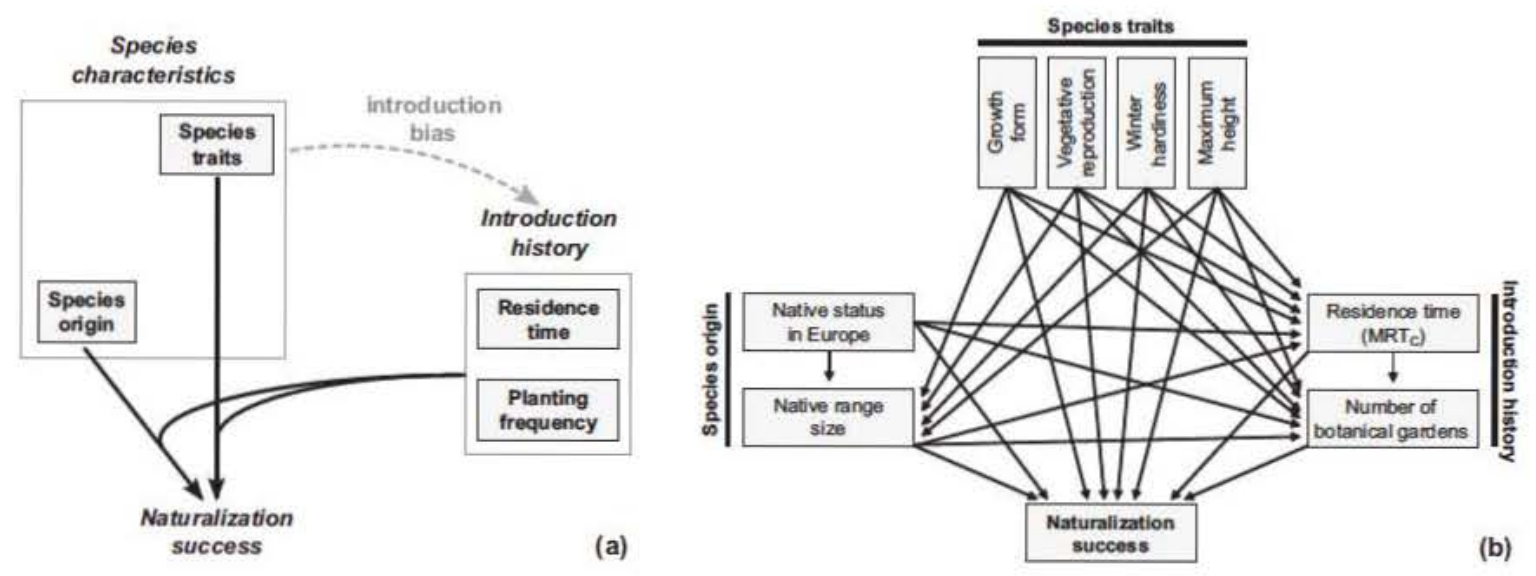

Figure 1 (a) Conceptual framework. Species characteristics and introduction history can directly affect naturalization success (black solid arrows). However, species characteristics may also partly determine introduction history (i.e. there may be an introduction bias, grey dashed arrow), thereby affecting naturalization success indirectly. (b) Full path model used to analyse the determinants of naturalization success. 
characteristics of species that are already naturalized could indirectly influence their invasion success (i.e. how widely they have naturalized) because of their introduction history. However, to the best of our knowledge, no study has yet ana lysed the role of introduction bias in the preceding stage of the invasion process, i.e. why some introduced alien plants successfully naturalized and others failed. Actually, very few studies have addressed this crucial early stage of the invasion process (Richardson \& Pyšek, 2012), mainly because such analysis requires data on failed naturalizations in order to avoid conflating the probabilities of introduction and natu ralization (Diez et al., 2009). The few studies that used such data (e.g. Dehnen Schmutz et al., 2007a; Hanspach et al., 2008; Bucharová \& van Kleunen, 2009; Pemberton \& Liu, 2009) did not disentangle direct effects of plant characteris tics on naturalization success from indirect effects due to introduction bias.

Of all the introduction pathways, ornamental trade is the largest source of naturalized and invasive plants (Reichard \& White, 2001; Lambdon et al., 2008). Because for some regions there are historical records about when and where certain ornamental plants have been introduced, these records offer the unique opportunity to test for an introduc tion bias and its consequences for naturalization success. In this study, we took advantage of a unique source on the year of ornamental plant introductions to Germany (Krausch, 2003). We combined these historical data with data on num bers of planting records in botanical gardens, geographical and biological characteristics and naturalization success of ornamental alien plant species in Germany in order to test their hypothesized relationships (Fig. 1b) using path analysis. Our study was guided by the following questions: (1) which species characteristics are associated with the minimum resi dence time in cultivation (time elapsed since the year of introduction) and/or the number of botanical gardens where the species has been planted (in other words, is there an introduction bias, and if so, of what direction and magni tude) and (2) how strong are direct and indirect effects of species characteristics on naturalization success?

\section{METHODS}

\section{Data compilation}

The test for an introduction bias is mainly restricted by the availability of data on the year of introduction. Therefore, we used as a basis for our study a unique dataset on vascular plant species introduced as ornamental garden plants in Germany. The list of plant species and the year of their intro duction to Germany was compiled from Krausch (2003). The author of that book carried out intensive research on the his tory of plant introductions in German gardens. As the list of species was compiled from a historical perspective, irrespec tive of the naturalization success of the species, it should be unbiased in this regard. However, because the list includes relatively few recently introduced species and few rarely planted species, the overall proportion of naturalized species on the list is likely to be higher than among all ornamental species. The year of introduction reported in Krausch (2003) is the earliest documented year of cultivation, with a main focus on gardens in Germany, and a few additional references to gardens in neighbouring countries. For 49 species, there was no exact year of introduction but a period of time that spanned up to 50 years. For these species, we took the mid dle of the reported period as the year of introduction (e.g. 1525 for 'first half of the 16th century'). As trans oceanic plant introductions mainly started after the discovery of the Americas, we excluded species introduced before 1492 (Pyšek et al., 2004). The 'minimum residence time since cultivation' $\left(\mathrm{MRT}_{\mathrm{C}}\right)$ was calculated as the number of years between 2015 and the year of introduction in cultivation. It differs from the minimum residence time that has been frequently used in plant invasion studies, and which refers to the time since first record of a species spontaneously growing in the wild (e.g. Pyšek \& Jarošík, 2005; Richardson \& Pyšek, 2006). We refer to this measure of residence time, which is obviously not available for non naturalized alien species, as 'minimum residence time in the wild' $\left(\mathrm{MRT}_{\mathrm{W}}\right)$.

Species names as reported in Krausch (2003) were standar dized according to the taxonomy of The Plant List (http:// www.theplantlist.org) using the $\mathrm{R}$ package 'Taxonstand' (Cayuela et al., 2012), with adjustments based on GRIN (http://pgrdoc.bioversity.cgiar.org/taxcheck/grin/index.html) and TNRS (http://tnrs.iplantcollaborative.org/index.html). Taxa reported at the infraspecific level were discarded when no match was found with the databases used for data on spe cies characteristics and planting intensity.

Planting intensity was estimated as the number of German botanical gardens where a species was cultivated (i.e. listed as an accession) according to the SysTax database during the period from 1989 (when the database was initiated) to 2005 (http://www.biologie.uni ulm.de/systax; using data from Hanspach et al., 2008). It is hereafter referred to as 'number of botanical gardens'. Although plantings in botanical gardens may not be representative of all ornamental plantings, and many naturalization events are likely to result from plantings in domestic gardens, botanical gardens are important focal introduction sites (e.g. Dawson et al., 2008), and plant ing records in botanical gardens correlate with other meas ures of planting intensity such as the number of companies having a species for sale (see Appendix S1 in Supporting Information).

We estimated native range size as the number of TDWG level 2 regions defined by the Biodiversity Information Standards (52 regions in total; Brummitt, 2001) where a spe cies is native, according to GRIN (http://www.ars grin.gov/ cgi bin/npgs/html/tax search.pl) and the Kew World Check list (http://apps.kew.org/wcsp/about.do). Native range size for our species ranged from 1 to 15 regions. In addition, we used these data to distinguish between 'European aliens' (i.e. species alien to Germany but native in other parts of Europe) and 'non European aliens' (i.e. species considered alien to all of Europe). 
For all species, data on biological traits were extracted from the European Garden Flora database (EGF; Cullen et al., 2011). We selected traits that were likely to be ecologi cally meaningful and have been reported as important for naturalization success in previous studies (e.g. Dehnen Schmutz et al., 2007b; Hanspach et al., 2008). Inclusion of traits was, however, limited to those that were available for most of our species: growth form (woody, perennial herb, annual herb), ability to reproduce vegetatively (yes, no), maximum height and winter hardiness (following the seven level EGF scale: H1 H5 and G1 G2; Cullen et al., 2011). As there were very few graminoids, we kept graminoids and forbs together as herbs. The two least hardy categories include species that are not frost hardy, and thus require cool (G1) or heated (G2) glasshouse protection during the winter in Germany. Given the very small number of species in cate gory G2, we merged the G1 and G2 categories.

We ended up with 435 ornamental alien species in the dataset. Naturalization status of these species in Germany was extracted from the DAISIE database (http://www.europe aliens.org, last accessed February 2014). A species was consid ered naturalized when the status for this species was 'alien established'. Of the 435 species, 79 (18\%) are considered naturalized.

Given that there are few species for which the year of introduction is known, the species in our dataset are a small subset of all garden plant species ever introduced to Ger many. Compared with other vascular plant species with avail able EGF trait data $(15,276$ species in total) species in our dataset are on average taller and hardier, and there is a smaller proportion of woody species and a higher proportion of annual herbs and European aliens (Appendix S2). Our dataset nevertheless covers to a large extent the entire range of levels of categorical traits and values of continuous traits found in the EGF. Therefore, deviations in average trait val ues between the dataset and the other ornamental species in Europe are unlikely to affect the representativeness of our results (Nakagawa, 2015).

\section{Statistical analyses}

\section{Imputation of missing data}

As is common for these kinds of data, the dataset contained missing trait values (up to $22.5 \%$ for the ability to reproduce vegetatively). Deletion of all species with incomplete entries would reduce sample size by $27 \%$ ( $n$ 316; see Appendix S2) and thus would reduce statistical power. In addition, deletion of these species could lead to misleading results because the data are not missing completely at random (see Appendix S2). We therefore imputed missing values of maximum height and ability to reproduce vegetatively using a nonpara metric iterative method based on the random forest algo rithm as implemented in the $\mathrm{R}$ package 'missForest' (Stekhoven \& Buhlmann, 2012). Imputation was repeated 100 times. We did imputations and all statistical analyses in R 3.1.1 (R Core Team, 2014).

\section{Path analysis}

Based on a priori hypotheses summarized in our conceptual framework (Fig. 1a), we built a path model to assess the drivers of naturalization success among introduced ornamen tal alien species. This model (Fig. 1b) included the following variables: naturalization success (binary variable), $\mathrm{MRT}_{\mathrm{C}}$ (continuous), number of botanical gardens (continuous), native status in Europe (binary), native range size (continu ous), winter hardiness (ordinal), growth form (categorical, but coded as three binary dummy variables), ability to repro duce vegetatively (binary) and maximum height (continu ous). In the path model, naturalization success (the probability of an introduced species becoming naturalized) could depend on all species characteristics and on $\mathrm{MRT}_{\mathrm{C}}$ and number of botanical gardens. Both $\mathrm{MRT}_{\mathrm{C}}$ and number of botanical gardens could also depend on any of the species characteristics (i.e. if there is an introduction bias). Because planting intensity could depend on time since introduction (i.e. time since introduction contributes to propagule pres sure), we also included a path from $\mathrm{MRT}_{\mathrm{C}}$ to number of botanical gardens. As species traits may determine the size of the native range (Pyšek et al., 2009b; Pyšek et al., 2015), we also included the corresponding paths. Additionally, we tested a path from native status in Europe to native range size, to account for the fact that species alien to Germany but native elsewhere in Europe had either a Eurasian or a large Mediterranean native distribution and were therefore more likely to occur as native in a larger number of regions. All continuous variables were standardized to a mean of zero and unit variance. To account for the correlation between growth form and maximum height (woody species are taller than most herbaceous ones), the latter was standardized within each growth form category.

As the assumption of multivariate normality was violated, we could not use path parameter estimation methods based on maximum likelihood. Therefore, we used a diagonally weighted least squares (DWLS) estimation method instead, and obtained standard errors of the parameter estimates from 1000 bootstraps. Path analyses were done for each of the 100 partially imputed datasets, and the results were aver aged across these 100 runs. The results of the path analysis done using partially imputed data were consistent with those of the path analysis done on the subset of species with com plete data (Appendix S3). Therefore, we consider the imputa tions to be reliable, and we present the results of the analysis that used partially imputed data.

All path analyses were done using the $\mathrm{R}$ packages 'lavaan' (Rosseel, 2012) and 'semTools' (semTools Contributors, 2015). To assess goodness of fit of the models, we calculated two absolute fit indices, the weighted root mean square resid ual (WRMR; Muthén \& Muthén, 1998 2010) and the gamma hat $(\hat{\gamma}$; Steiger, 1989), which is derived from the goodness of fit index, and one incremental ( relative) fit index, the comparative fit index (CFI; Bentler, 1990), which compares the fit of the tested model to the fit of a null model. Model 
fit is considered to be good when WRMR $<1, \hat{\gamma}>0.95$ and CFI $>0.95$ (Hu \& Bentler, 1999). The three fit indices all met the standard criteria: CFI $0.983, \hat{\gamma} \quad 0.992$, WRMR 0.463 . Moreover, there was no large value in the residual covariance matrix, which also indicates that the model fitted the data. To evaluate the amount of variation in naturalization success explained by our model we calculated the $R^{2}$ value.

Path analysis provides insights into direct and indirect effects that cannot be achieved with other statistical approaches. A disadvantage of path analysis involving non continuously distributed data such as we had (naturalization success as binary data) is that it is not straightforward to account for phylogenetic non independence of species. How ever, while we found significant phylogenetic signals for most variables, these signals were of relatively small magnitude (Appendix S4). Therefore, the lack of phylogenetic correction in our analysis should have minor effects on the results.

\section{RESULTS}

Path analysis disentangled the direct and indirect effects underlying the patterns of association between naturalization success and species characteristics depicted in Fig. 2. Direct and indirect effects of species characteristics jointly explained $26.9 \%$ of the variation in naturalization success (Fig. 3, Appendix S3).

\section{Direct effects of introduction history and species characteristics on naturalization success}

$\mathrm{MRT}_{\mathrm{C}}$ did not directly affect naturalization success, but number of botanical gardens had a significant positive direct effect (Fig. 3). Despite apparent associations between most species characteristics and naturalization success (Fig. 2), only native range size and winter hardiness had significant direct effects on naturalization success (Fig. 3). The effects of these two characteristics were positive. The other four species characteristics had no significant direct effects on naturaliza tion success.

\section{Introduction bias}

Alien plant species native to other parts of Europe were introduced to Germany significantly earlier (Figs 3 \& $4 a$ ) than non European ones. In addition, these so called Euro pean aliens had larger native ranges, and native range size had a positive effect on $\mathrm{MRT}_{\mathrm{C}}$ (Figs $3 \& 4 \mathrm{~b}$ ).

Number of botanical gardens was significantly positively associated with increasing $\mathrm{MRT}_{\mathrm{C}}$ (Fig. 3). Annual and peren nial herbs were planted in significantly fewer German botani cal gardens than woody species (Figs 3 \& $4 \mathrm{c}$ ). Winter hardiness had a significantly positive effect on number of botanical gardens (Figs 3 \& 4d). Number of botanical gar dens tended to be positively associated with maximum height (standardized within each growth form category), but the relationship was not significant $\left(\begin{array}{ll}P & 0.062\end{array}\right)$. (a)

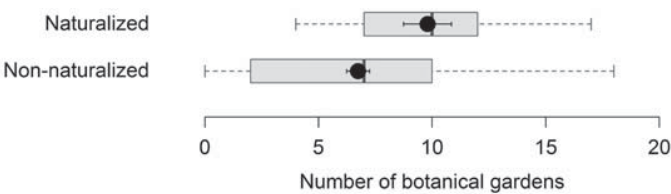

(b)

Naturalized Non-naturalized

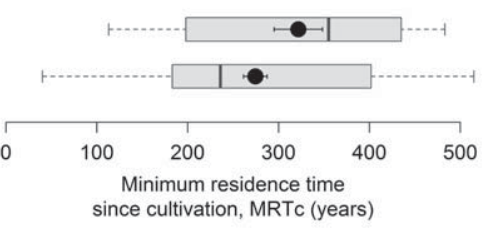

(c)

Naturalized Non-naturalized
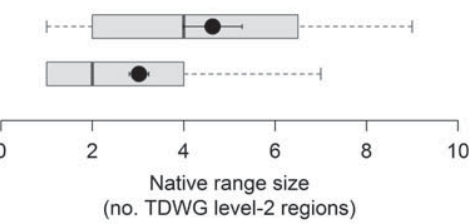

(d)

Naturalized

Non-naturalized

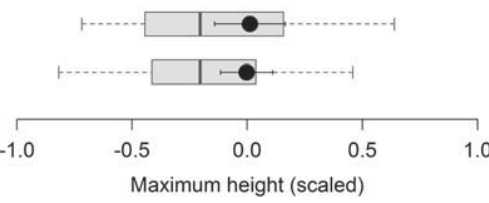

(e)

European aliens Non-European aliens

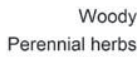
Perennial herbs
Annual herbs

$$
\text { Vegetative }
$$$$
\text { No vegetative }
$$

(h)

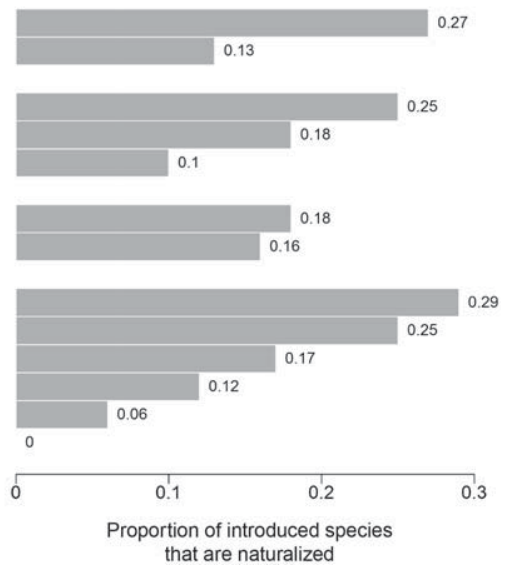

Figure 2 Observed relationship between naturalization success of ornamental alien plants in Germany and (a) number of botanical gardens, (b) minimum residence time since cultivation $\left(\mathrm{MRT}_{\mathrm{C}}\right),(\mathrm{c})$ native range size, (d) maximum height, (e) native status in Europe, (f) growth form, (g) ability to reproduce vegetatively and (h) winter hardiness. Solid circles and error bars in (a) (d) are the mean values and the $95 \%$ confidence intervals, respectively. Boxplots display the median and the interquartile range. In (e) (h) the actual values are given next to each bar. Note that the plotted data represent the observed net effect resulting from both direct and indirect effects, not the direct effects alone. For example, the apparent effects of native status in Europe and of growth form (e, f) are due to an introduction bias (Fig. 4a, c). While path analysis allowed us to show how a particular species characteristic could influence naturalization success either directly or indirectly (or both), univariate analysis could have potentially led to erroneous conclusions on the proper role of this characteristic (see the results of univariate linear generalized models in Appendix S6). 


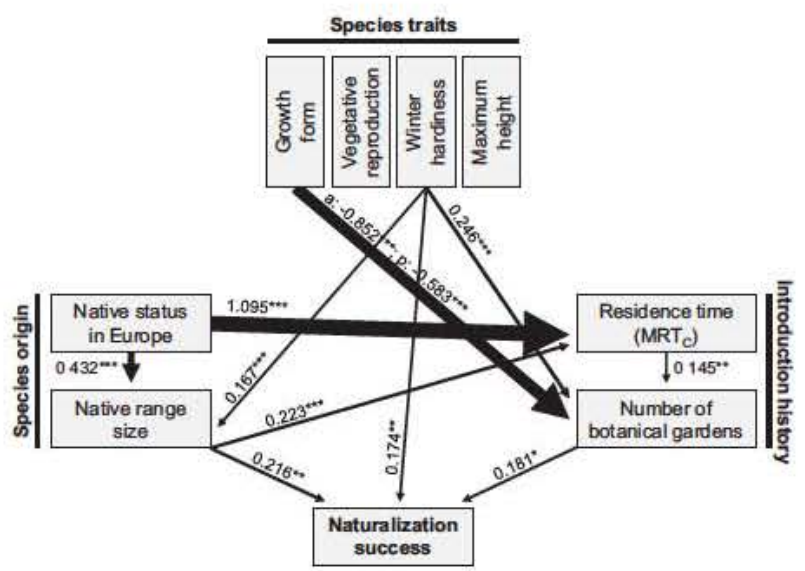

Figure 3 Results of path analysis for naturalization success of ornamental alien plants in Germany. Significant paths $(P<0.05)$ are displayed, with the significance indicated with asterisks $\left({ }^{* *} P<0.001,{ }^{* *} 0.001<P<0.01,{ }^{*} 0.01<P<0.05\right)$. Non significant paths $(P>0.05)$ are not displayed. Path coefficient estimates provide a measure of the importance of the relationship (the larger the coefficient, the stronger the relationship). The thickness of an arrow is proportional to the value of the path coefficient estimate. For the effects of growth form, 'a' refers to annual herbs and ' $\mathrm{p}$ ' to perennial herbs, both relative to woody species. See Appendix S3 for the detailed results of path analyses.

\section{Relative importance of direct and indirect effects of species characteristics on naturalization}

Two characteristics, native range size and winter hardiness, had both direct and indirect significant effects on naturaliza tion success. For native range size, the indirect effect accounted for just $3 \%$ of the total effect (indirect effect, 0.006 ; direct effect, 0.216 ), whereas for winter hardiness it accounted for $32 \%$ of the total effect (indirect effect, 0.082 ; direct effect, 0.174). Native status in Europe and growth form only indirectly affected naturalization success. Maxi mum height and the ability to reproduce vegetatively did not influence naturalization success significantly, neither directly nor indirectly.

\section{DISCUSSION}

By using path analysis, we demonstrated that the effects of several species characteristics on naturalization success here in particular the size of a species' native range, whether it is native to other parts of Europe outside Germany, as well as its growth form and winter hardiness are mediated by introduction bias (Fig. 3). This bias results from the fact that ornamental species with certain characteristics were intro duced earlier or more frequently than others, and that the minimum residence time since cultivation, that is how long ago the species has been brought into cultivation in the country, correlated with number of botanical gardens, which in turn increased the probability of naturalization. So, the net effect, i.e. the sum of direct and indirect effects, of species characteristics on naturalization success may not just reflect a direct causal relationship, unlike often assumed in macroecological studies on invasions.

Of the six species characteristics included in our study, native range size and winter hardiness had significant direct effects on naturalization success in Germany. Species with a large native range were more likely to naturalize than those with a smaller range. It has been argued that a large native range indicates that the species has a high environmental tolerance or versatility (Dehnen Schmutz et al., 2007a,b; Hanspach et al., 2008) and a high dispersibility (Gaston, 2003), or has a large chance of being picked up and intro duced elsewhere (Pyšek et al., 2004; van Kleunen et al., 2007; Gravuer et al, 2008). As the latter non biological explanation was explicitly accounted for in the path analysis, the direct effect on naturalization success suggests that native range size is associated with biological traits that promote naturaliza tion. Winter hardiness also substantially increased naturaliza tion success directly. This is in line with the findings of previous studies (Dehnen Schmutz et al., 2007a; Hanspach et al., 2008), and reflects the fact that the ability of a species to cope with frost largely determines the areas where it can establish self sustaining populations (Pither, 2003). So, our path analysis revealed evidence for direct causal relationships between species characteristics and naturalization.

In addition to direct effects of species characteristics, natu ralization success was also directly affected by the introduc tion history of the species (Fig. 3). The more widely a species was planted in German botanical gardens, the more likely it was to naturalize. This reflects that planting intensity is a major component of propagule pressure, which is widely acknowledged to be a major driver of naturalization and invasion of alien plants (Lockwood et al., 2005; Pyšek et al., 2009a; Richardson \& Pyšek, 2012; Pyšek et al., 2015).

We found no direct effect of $\mathrm{MRT}_{\mathrm{C}}$ on naturalization suc cess in Germany. Although some studies (Bucharová \& van Kleunen, 2009; McGregor et al., 2012) also found weak effects of residence time since cultivation on naturalization success, our finding seems remarkable given that many other studies have indicated a positive association between inva siveness of naturalized species and residence time. One expla nation could be that our dataset was biased against recent introductions, which means that the majority of species should have had enough time to become naturalized. In other words, time was not a limiting factor, and residence time thus did not appear as a predictor of naturalization suc cess. Another explanation could be that, with few exceptions (e.g. Phillips et al., 2010), previous studies measured resi dence time as time since the earliest documented occurrence in the wild (e.g. Pyšek et al., 2009a; Williamson et al., 2009; Pyšek et al., 2015). $\mathrm{MRT}_{\mathrm{W}}$ is likely to be closely related to the success of an alien species because the longer a species occurs in the wild in a given region the more time it has had to spread. Although our $\mathrm{MRT}_{\mathrm{C}}$ measure is closely correlated with $\mathrm{MRT}_{\mathrm{W}}$ for those species that do naturalize (Appendix S5), its non significant contribution to naturalization could 


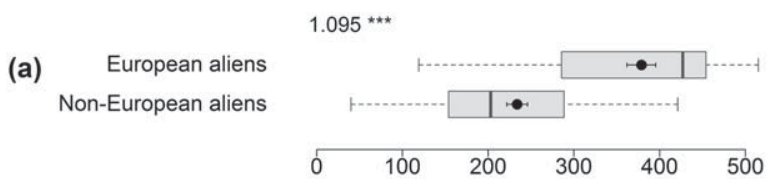

(b)

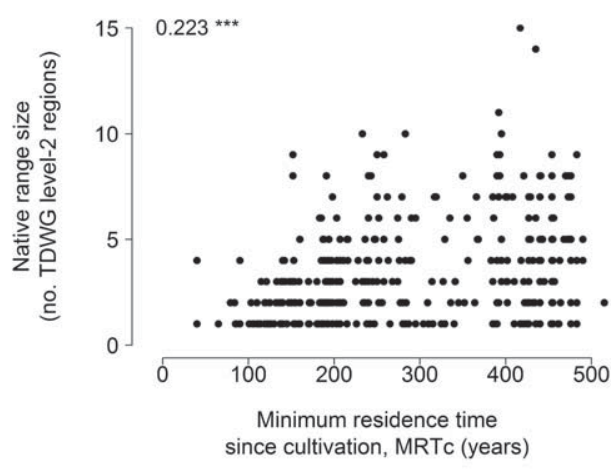

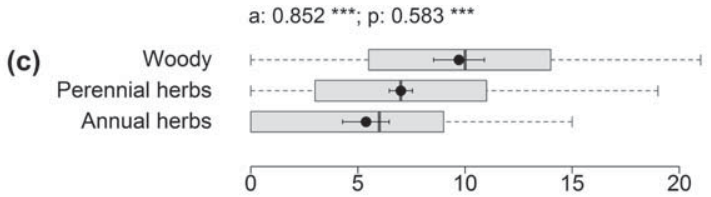

0.246 ***

(d)

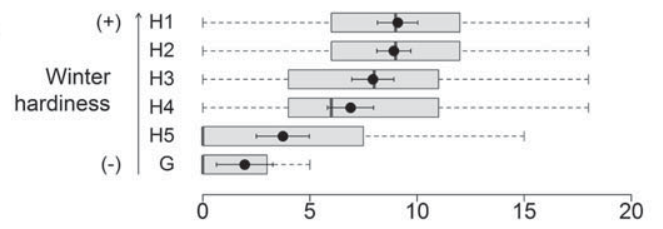

(e)

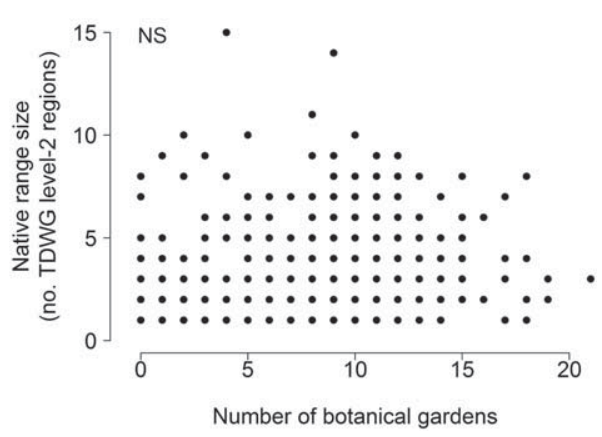

Figure 4 Introduction bias: observed relationship between (a) native status in Europe, (b, e) native range size, (c) growth form, and (d) winter hardiness, and (a b) $\mathrm{MRT}_{\mathrm{C}}$ or (c e) number of botanical gardens. In (a), (d) and (e), solid circles show the mean values for Germany; error bars are the $95 \%$ confidence intervals; boxplots display the median and the interquartile range. On each graph, we provide the path coefficient estimate of the corresponding path, and its significance in brackets: ${ }^{\star *}{ }^{*} P<0.001$; ${ }^{*} 0.001<P<0.01$; ${ }^{\star} 0.01<P<0.05$; NS, $P>0.05$ (not significant). For the effects of growth form, 'a' refers to annual herbs and 'p' to perennial herbs, both relative to woody species. Note that native range size had no direct effect on number of botanical gardens (e) but had an indirect one through $\mathrm{MRT}_{\mathrm{C}}$ (Figs $3 \& 4 \mathrm{~b}$ ), which contributes to the pattern in (c).

indicate that the majority of alien species introduced to culti vation fail to naturalize, irrespective of how long they have been present in cultivation.

Most European aliens were introduced earlier to Germany than non European ones. It is likely that European aliens were more readily available, as they were easier to obtain due to geographical proximity (Pyšek et al., 2003). European origin was also positively related to native range size. This most likely reflects that many European aliens have a Eura sian or Mediterranean distribution (Pyšek et al., 2012), and therefore are native to a large number of regions. Although our path analysis model accounted for this correlation, native range size was also directly positively associated with $\mathrm{MRT}_{\mathrm{C}}$. This indicates that native range size is not only indicative of biological characteristics that directly promote naturalization, but also that having a large native range increases the probability of being picked up and introduced elsewhere in the world. Thus, native range size promotes naturalization success directly and indirectly, via an intro duction bias.
We also found evidence for an introduction bias with regard to two of the four species characteristics. In particular, growth form showed a strong introduction bias; annual and perennial herbs had much lower planting frequencies than woody species. Such an introduction bias may also have con tributed to the reported lower probability of naturalization for annuals in other European countries, such as Great Brit ain (Dehnen Schmutz et al., 2007b). It might also partly reflect that, because woody species have a longer life span than annual herbs and most perennial herbs, they have a lower turn over in gardens. Plantings recorded over a rela tively short time interval may therefore integrate actual plantings over a longer time period. Finally, hardier species were planted more frequently, suggesting that botanical gar dens tend to prefer species that are more resistant to frost and thus do not require glasshouse protection in winter. Other studies also highlighted the role of winter hardiness for escape from gardens (Dehnen Schmutz et al., 2007b) and for naturalization success (Hanspach et al., 2008). Here, we thus show for the first time that some of the associations 
between species characteristics and naturalization might at least partly reflect indirect effects through associations between species characteristics and planting intensity.

The amount of variation in naturalization success explained by our path analysis model $(26.9 \%)$ may seem rel atively small, which suggests that we did not include all the important drivers of naturalization. It is nevertheless reason ably good for an analysis of this kind (see, e.g., Dehnen Schmutz et al., 2007b; Küster et al., 2008; Pemberton \& Liu, 2009), particularly given the small number of species charac teristics and other drivers considered. The large amount of variation left unexplained could also indicate that we only partly captured the role of propagule pressure. The general scarcity of species specific data on the different components of propagule pressure is an important limitation to disentan gling the drivers of plant naturalization success. Not only are data on propagule size (sensu Lockwood et al., 2005) missing, but the nature of the data for propagule number (sensu Lockwood et al., 2005) can be very influential. Quantitative measures based on the frequency of marketing or planting are so far the best proxies available for large numbers of plant species. Both types of measures may vary substantially depending on the pool of sources (e.g. nursery catalogues, botanical garden records) used. Importantly, such data are typically available for one or a few points in time, all concen trated in the last few decades. Given that horticulture is sub ject to fashion trends and historical changes, any of those measures is unlikely to be constant over time (see, e.g., Dehnen Schmutz et al., 2007a). In the absence of historical data from previous centuries, one must therefore assume that modern planting data reflect to a certain extent past plant ings and thus past propagule pressure. The fact that we found significant effects of number of botanical gardens on naturalization success and of residence time on number of botanical gardens, gives support to this assumption. In this regard, the test for these relationships can be considered to be conservative, and it is thus likely that the true role of introduction history has been even larger than suggested by our results.

\section{CONCLUSIONS}

For species characteristics to have substantial indirect effects on naturalization, there must at the same time be a signifi cant introduction bias and an effect of time and/or frequency of introduction on naturalization success. Our dataset was a relatively small and biased sample of all ornamental alien plant species introduced to Germany, making our analysis a conservative test of the existence of introduction biases and of their consequences on naturalization success. Using path analysis, we detected an introduction bias with regard to sev eral species characteristics. Because number of botanical gar dens increased naturalization success directly, and residence time did so indirectly through a significant positive associa tion with number of botanical gardens, several species char acteristics examined in our study had indirect effects on naturalization. The size and relative importance of direct and indirect effects depends partly on the data used. Although most of the indirect effects in our study were small in magni tude, the general consequences of an introduction bias could be large. When direct and indirect effects act in the same direction as was the case for winter hardiness in our study

failure to recognize the existence of an introduction bias would lead to an overestimation of the true effect of species characteristics. Direct and indirect effects could also act in opposite directions, for example when a characteristic pro motes naturalization success but species with that character istic are avoided by gardeners. This could result in spurious relationships between species characteristics and naturaliza tion success, or the direct and indirect effects could cancel out, and mask the true importance of a given characteristic. Therefore to gain a better understanding of what drives natu ralization of alien species, we advocate a more systematic assessment of potential biases in the history of introduction of alien plants.

\section{ACKNOWLEDGEMENTS}

M.v.K. and N.M. thank the DFG for funding (grant KL 1866/5 1). P.P. was supported by project no. $1436079 \mathrm{G}$, Centre of Excellence PLADIAS (Czech Science Foundation), long term research development project RVO 67985939 (The Czech Acad emy of Sciences), and acknowledges support from The Czech Academy of Sciences (Praemium Academiae award). We thank Wayne Dawson for English corrections.

\section{REFERENCES}

Bentler, P.M. (1990) Comparative fit indexes in structural models. Psychological Bulletin, 107, 238246.

Blackburn, T. \& Duncan, R. (2001) Establishment patterns of exotic birds are constrained by non random patterns in introduction. Journal of Biogeography, 28, 927939.

Blackburn, T.M., Pyšek, P., Bacher, S., Carlton, J.T., Duncan, R.P., Jarošík, V., Wilson, J.R.U. \& Richardson, D.M. (2011) A proposed unified framework for biological invasions. Trends in Ecology and Evolution, 26, 333339.

Brummitt, R.K. (2001) World geographical scheme for record ing plant distributions, 2nd edn. Hunt Institute for Botani cal Documentation, Carnegie Mellon University, Pittsburgh, PA.

Bucharová, A. \& van Kleunen, M. (2009) Introduction his tory and species characteristics partly explain naturalization success of North American woody species in Europe. Jour nal of Ecology, 97, 230238.

Capellini, I., Baker, J., Allen, W.L., Street, S.E. \& Venditti, C. (2015) The role of life history traits in mammalian inva sion success. Ecology Letters, 18, 10991107.

Cassey, P., Blackburn, T., Jones, K. \& Lockwood, J. (2004a) Mistakes in the analysis of exotic species establishment: source pool designation and correlates of introduction suc cess among parrots (Aves: Psittaciformes) of the world. Journal of Biogeography, 31, 277284. 
Cassey, P., Blackburn, T., Russell, G., Jones, K. \& Lockwood, J. (2004b) Influences on the transport and establishment of exotic bird species: an analysis of the parrots (Psittaci formes) of the world. Global Change Biology, 10, 417426.

Cayuela, L., Granzow de la Cerda, I., Albuquerque, F.S. \& Golicher, D.J. (2012) TAXONSTAND: an R package for species names standardisation in vegetation databases. Methods in Ecology and Evolution, 3, 10781083.

Chrobock, T., Kempel, A., Fischer, M. \& van Kleunen, M. (2011) Introduction bias: cultivated alien plant species ger minate faster and more abundantly than native species in Switzerland. Basic and Applied Ecology, 12, 244250.

Colautti, R. (2005) Are characteristics of introduced salmo nid fishes biased by propagule pressure? Canadian Journal of Fisheries and Aquatic Sciences, 62, 950959.

Cullen, J., Knees, S. \& Cubey, H.S. (2011) The European gar den flora. A manual for the identification of plants cultivated in Europe, both out of doors and under glass, 2nd edn. Cambridge University Press, Cambridge.

Dawson, W., Mndolwa, A.S., Burslem, D.F.R.P. \& Hulme, P.E. (2008) Assessing the risk of plant invasions arising from collections in tropical botanical gardens. Biodiversity and Conservation, 17, 19791995.

Dehnen Schmutz, K, Touza, J, Perrings, C. \& Williamson, M. (2007a) A century of the ornamental plant trade and its impact on invasion success. Diversity and Distributions, 13, 527534.

Dehnen Schmutz, K., Touza, J., Perrings, C. \& Williamson, M. (2007b) The horticultural trade and ornamental plant invasions in Britain. Conservation Biology, 21, 224231.

Diez, J.M., Williams, P.A., Randall, R.P., Sullivan, J.J., Hulme, P.E. \& Duncan, R.P. (2009) Learning from failures: testing broad taxonomic hypotheses about plant naturalization. Ecology Letters, 12, 11741183.

Donaldson, J.E., Hui, C., Richardson, D.M., Robertson, M.P., Webber, B.L. \& Wilson, J.R.U. (2014) Invasion trajectory of alien trees: the role of introduction pathway and planting history. Global Change Biology, 20, 15271537.

Gaston, K.J. (2003) The structure and dynamics of geographic ranges. Oxford University Press, Oxford.

Gravuer, K., Sullivan, J.J., Williams, P.A. \& Duncan, R.P. (2008) Strong human association with plant invasion suc cess for Trifolium introductions to New Zealand. Proceedings of the National Academy of Sciences USA, 105, 63446349.

Hanspach, J., Kühn, I., Pyšek, P., Boos, E. \& Klotz, S. (2008) Correlates of naturalization and occupancy of introduced ornamentals in Germany. Perspectives in Plant Ecology, Evo lution and Systematics, 10, 241250.

Hu, L.T. \& Bentler, P.M. (1999) Cutoff criteria for fit indexes in covariance structure analysis: conventional criteria versus new alternatives. Structural Equation Modeling, 6, 155.

van Kleunen, M., Johnson, S.D. \& Fischer, M. (2007) Predict ing naturalization of southern African Iridaceae in other regions. Journal of Applied Ecology, 44, 594603.

van Kleunen, M., Weber, E. \& Fischer, M. (2010a) A meta analysis of trait differences between invasive and non invasive plant species. Ecology Letters, 13, 235245. van Kleunen, M., Dawson, W., Schlaepfer, D., Jeschke, J.M. \& Fischer, M. (2010b) Are invaders different? A conceptual framework of comparative approaches for assessing deter minants of invasiveness. Ecology Letters, 13, 947958.

van Kleunen, M., Dawson, W. \& Maurel, N. (2015a) Charac teristics of successful alien plants. Molecular Ecology, 24, 19541968.

van Kleunen, M., Dawson, W., Essl, F. et al. (2015b) Global exchange and accumulation of non native plants. Nature, 525, 100103.

Krausch, H.D. (2003) "Kaiserkron und Päonien rot ..."Von der Entdeckung und Einführung unserer Gartenblumen. Dölling und Galitz Verlag GmbH, Munich.

Kueffer, C., Pyšek, P. \& Richardson, D.M. (2013) Integrative invasion science: model systems, multi site studies, focused meta analysis and invasion syndromes. New Phytologist, 200, 615633.

Küster, E., Kühn, I., Bruelheide, H. \& Klotz, S. (2008) Trait interactions help explain plant invasion success in the Ger man flora. Journal of Ecology, 96, 860868.

Lambdon, P.W., Pyšek, P., Basnou, C. et al. (2008) Alien flora of Europe: species diversity, temporal trends, geographical patterns and research needs. Preslia, 80, 101149.

Leadley, P., Pereira, H.M., Fernandez Manjarrés, J.F., Proença, V., Scharlemann, J.P.W. \& Walpole, M.J. (2010) Biodiversity scenarios: projections of 21st century change in biodiversity and associated ecosystem services. Technical report for the Global Biodiversity Outlook 3. Secretariat of the Conven tion on Biological Diversity, Montreal, QC.

Lockwood, J.L., Cassey, P. \& Blackburn, T. (2005) The role of propagule pressure in explaining species invasions. Trends in Ecology and Evolution, 20, 223228.

McGregor, K.F., Watt, M.S., Hulme, P.E. \& Duncan, R.P. (2012) What determines pine naturalization: species traits, climate suitability or forestry use? Diversity and Distribu tions, 18, 10131023.

Muthén, L.K. \& Muthén, B.O. (1998 2010) MPlus user's guide, 6th edn. Muthén and Muthén, Los Angeles, CA.

Nakagawa, S. (2015) Missing data: mechanisms, methods, and messages. Ecological statistics: contemporary theory and application (ed. by G.A. Fox, S. Negrete Yankelevich and V.J. Sosa), pp. 81 105. Oxford University Press, Oxford.

Pemberton, R.W. \& Liu, H. (2009) Marketing time predicts naturalization of horticultural plants. Ecology, 90, 6980.

Phillips, M.L., Murray, B.R., Leishman, M.R. \& Ingram, R. (2010) The naturalization to invasion transition: are there introduction history correlates of invasiveness in exotic plants of Australia? Austral Ecology, 35, 695703.

Pither, J. (2003) Climate tolerance and interspecific variation in geographic range size. Proceedings of the Royal Society B: Biological Sciences, 270, 475481.

Pyšek, P. \& Jarošík, V. (2005) Residence time determines the distribution of alien plants. Invasive plants: ecological and agricultural aspects (ed. by S. Inderjit), pp. 7796. Birkhäuser Verlag, Basel. 
Pyšek, P. \& Richardson, D.M. (2007) Traits associated with invasiveness in alien plants: where do we stand? Biological invasions (ed. by W. Nentwig), pp. 97 125. Springer, Berlin.

Pyšek, P., Sádlo, J., Mandák, B. \& Jarošík, V. (2003) Czech alien flora and the historical pattern of its formation: what came first to Central Europe? Oecologia, 135, 122130.

Pyšek, P., Richardson, D.M. \& Williamson, M. (2004) Pre dicting and explaining plant invasions through analysis of source area floras: some critical considerations. Diversity and Distributions, 10, 179187.

Pyšek, P., Křivánek, M. \& Jarošík, V. (2009a) Planting inten sity, residence time, and species traits determine invasion success of alien woody species. Ecology, 90, 27342744.

Pyšek, P., Jarošík, V., Pergl, J., Randall, R., Chytrý, M., Kühn, I., Tichy, L., Danihelka, J., Chrtek, J.J. \& Sádlo, J. (2009b) The global invasion success of Central European plants is related to distribution characteristics in their native range and species traits. Diversity and Distributions, 15, 891903.

Pyšek, P., Chytrý, M., Pergl, J., Sádlo, J. \& Wild, J. (2012) Plant invasions in the Czech Republic: current state, intro duction dynamics, invasive species and invaded habitats. Preslia, 84, 575629.

Pyšek, P., Manceur, A.M., Alba, C., McGregor, K.F., Pergl, J., Štajerová, K., Chytrý, M., Danihelka, J., Kartesz, J., Klimešová, J., Lučanová, M., Moravcová, L., Nishino, M., Sádlo, J., Suda, J., Tichý, L. \& Kühn, I. (2015) Naturalization of central Euro pean plants in North America: species traits, habitats, propa gule pressure, residence time. Ecology, 96, 762774.

R Core Team (2014) R: a language and environment for statis tical computing. R Foundation for Statistical Computing, Vienna, Austria.

Reichard, S.H. \& White, P. (2001) Horticulture as a pathway of invasive plant introductions in the United States. Bio science, 51, 103113.

Richardson, D.M. \& Pyšek, P. (2006) Plant invasions: merg ing the concepts of species invasiveness and community invasibility. Progress in Physical Geography, 30, 409431.

Richardson, D.M. \& Pyšek, P. (2012) Naturalization of intro duced plants: ecological drivers of biogeographical patterns. New Phytologist, 196, 383396.

Rosseel, Y. (2012) lavaan: an R package for structural equa tion modeling. Journal of Statistical Software, 48, 136.

semTools Contributors (2015) semTools: Useful tools for struc tural equation modeling. $\mathrm{R}$ package version 0.4 9. Available at: http://cran.r project.org/package semTools.
Shipley, B (2000) Cause and correlation in biology. A user's guide to path analysis, structural equations and causal infer ence. Cambridge University Press, Cambridge.

Steiger, J.H (1989) EzPATH: a supplementary module for SYSTAT and SYGRAPH. SYSTAT, Inc., Evanston, IL.

Stekhoven, D.J. \& Buhlmann, P. (2012) MissForest non para metric missing value imputation for mixed type data. Bio informatics, 28, 112118.

Williamson, M., Dehnen Schmutz, K., Kühn, I., Hill, M., Klotz, S., Milbau, A., Stout, J. \& Pyšek, P. (2009) The dis tribution of range sizes of native and alien plants in four European countries and the effects of residence time. Diversity and Distributions, 15, 158166.

\section{SUPPORTING INFORMATION}

Additional supporting information may be found in the online version of this article at the publisher's web site:

Appendix S1 Comparisons between measures of planting intensity.

Appendix S2 Biases in the dataset: representativeness of the data on species characteristics; patterns of missing trait data. Appendix S3 Results of path analysis performed on imputed data versus on complete cases alone.

Appendix S4 Test for phylogenetic signals in species characteristics.

Appendix S5 Relationship between minimum residence time since cultivation $\left(\mathrm{MRT}_{\mathrm{C}}\right)$ and minimum residence time in the wild $\left(\mathrm{MRT}_{\mathrm{W}}\right)$.

Appendix S6 Results of univariate generalized linear models. 